\title{
Complex Dynamical Systems in Human Development
}

\author{
Ralf F. A. Cox $\mathbb{D},{ }^{1}$ Ruud J. R. Den Hartigh $\mathbb{D},{ }^{1}$ Michael J. Richardson $\mathbb{D},{ }^{2}$ \\ Chen $Y u\left(D,{ }^{3}\right.$ and Till D. Frank $\left(\mathbb{D}^{4}\right.$ \\ ${ }^{1}$ Department of Psychology, University of Groningen, Groningen, Netherlands \\ ${ }^{2}$ Department of Psychology, Macquarie University, Sydney, Australia \\ ${ }^{3}$ Department of Psychological and Brain Sciences, Indiana University, Bloomington, IN, USA \\ ${ }^{4}$ Department of Psychological Sciences and Department of Physics, University of Connecticut, Storrs, CT, USA
}

Correspondence should be addressed to Ralf F. A. Cox; r.f.a.cox@rug.nl

Received 10 June 2019; Accepted 10 June 2019; Published 1 July 2019

Copyright (c) 2019 Ralf F. A. Cox et al. This is an open access article distributed under the Creative Commons Attribution License, which permits unrestricted use, distribution, and reproduction in any medium, provided the original work is properly cited.

Researchers from the complex dynamical systems perspective seek their explanations of human behavior and development in the dynamical interactions across many levels in an active, situated individual. That is to say, behavior and development are both constraining and constrained by the continuous exchange between a myriad of processes distributed across brain, body, and environment. This fundamentally questions the more traditional rationale that behavior and development of any kind can be explained by targeting a low number of domain-specific, static components or environmental factors [1-5]. In such a mechanistic approach, components are typically thought to exert their causal effects in a chainlike fashion [e.g., [6]], and development is explained by the function and place of the components in the chain. However, compiling evidence demonstrates that human behavior and development are dynamic, multiscaled, and emergent phenomena. It is for this reason that they should be studied from a complex dynamical systems perspective.

In order to address the massive interactionism that underlies behavior, and how it leads to developmental changes, we need a conceptual and methodological framework that can capture properties such as nonlinearity, self-organization, pattern formation, attractors, nested time scales, fractal scaling, and (inter-personal) synchrony. These properties have been widely observed in the domain of human development $[7,8]$. Therefore, techniques are needed that enable a detailed analysis of the temporal structure in time series and that can handle both intraindividual and interindividual variability in developmental datasets, preferably in combination.
Intraindividual variability needs to be studied both at the shorter timescales of the unfolding behavior and at the longer timescales of the developmental changes. Interindividual variability is a typical (almost defining) feature of development and needs to be addressed in any serious account of a developmental phenomenon. Importantly, both types of variability underline the importance of the complex dynamical systems perspective.

The properties of complex dynamical systems mentioned above can be detected and quantified by using techniques from the toolbox of nonlinear dynamics [9]. In the social sciences there is an increase in the use of nonlinear time series analysis and dynamical modeling as a means to study human development. Advancements are made in developing and applying techniques such as recurrence quantification analyses and longitudinal network modeling. The application of such techniques has led to insights in human developmental processes, which would not come to the fore with more "traditional" techniques [10-13].

This special issue has brought together a number of interesting articles that showcase the various methodologies related to the complex dynamical systems perspective and how they can be applied on a wide range of topics. The collection of papers demonstrates how the complex dynamical systems perspective can be useful in two ways: firstly, by advancing theoretical insights into human development, leading also to novel research questions; secondly, by offering a rich set of related analysis and modelling techniques that can be applied to human data, giving rise also to innovative 
data-collection procedures. Seven articles were published out of the many articles that were submitted to this special issue from all around the world. The quality and diversity of the articles denote the impact and relevance of complex dynamical systems in human development.

In the article "Does Competence Determine Who Leads in a Dyadic Cooperative Task? A Study of Children with and without a Neurodevelopmental Disorder" by R. Vink et al., the collaborative dynamics of typical children as well as children with a neurodevelopmental disorder is investigated. In order to determine dyadic synchronization, children's postural sway, while they perform tangram puzzles together, is analyzed using recurrence quantification analysis. Interesting differences between typically developing children and children with neurodevelopmental disorders are revealed, in terms of the relation between the dyads performance, the ability level of each dyad members, and who leads and who follows in the interaction. The authors stress that the analyses they applied are insightful, and that they are relevant because of the importance of cooperative learning for academic performance.

In the article "Development and Complex Dynamics at School Environment" by M. A. Fuentes et al., the complex dynamical systems approach is used to study peer interactions in a learning environment, but with a focus on social network plasticity. In their work the authors assess the effectiveness of a school-based intervention. Quantitative work is presented on the impact of cooperative and selfawareness activities on behavioral plasticity of social relationships amongst 6-7-year-old children. Complex networks and game theory are employed to analyze the changes in the patterns of social relationships due to the intervention, in comparison to a control group. The intervention proves to have positive effects on social interactions, amongst other things by enhancing children's positive networks.

In the article "Socioemotional Dynamics of Emotion Regulation and Depressive Symptoms: A Person-Specific Network Approach" by X. Yang et al., experience sampling data of over one year from a large group of participants is reported in the context of depression. The socioemotional processes of daily social interactions and the regulation of negative emotions are studied, with special emphasis on intraindividual differences and change. Relations are revealed between depressive symptoms on the one hand and the length of recovery time and stressful life events on the other. The person-specific network approach to study (changes in) emotion regulation in individuals, as applied in this article, exemplifies the complex dynamical systems approach to the study of psychological health.

In the article "Self-Esteem as a Complex Dynamic System: Intrinsic and Extrinsic Microlevel Dynamics" by N. M. P. de Ruiter et al., the focus is on intraindividual variability and attractor states of (state) self-esteem in adolescents. The authors develop and test their Self-Organizing SelfEsteem model, which is based on interactions between a person's social context and the intrinsic dynamics of selfesteem resulting from higher-order self-esteem attractors. Using Kohonen's self-organizing maps and state space grids, this study tests the levels of self-esteem attractors and how this determines the influence of changes in the immediate context (e.g., parental support) on self-esteem variability.

In the article "Developmentally Changing Attractor Dynamics of Manual Actions with Objects in Late Infancy", J. I. Borjon et al. also focus on attractor dynamics, but in the context of infants' motor development. The authors are interested in how order in manual actions arises and seek its explanation through developmental changes in attractor dynamics. In a longitudinal study, they analyze the dynamics of manual actions during the first two years of infants' lives. The authors introduce and apply a new technique for studying attractors properties, like attractor size and dwell time, and show how these change across development. Their analyses are based on motion data of infants limb effectors while they interact with toys.

In the article "The Development of Talent in Sports: A Dynamic Network Approach", R. J. R. Den Hartigh et al. investigate talent development using a dynamic network modeling approach. Their dynamic network model predicts typical individual developmental patterns, which closely correspond to the patterns observed in different famous athletes. Next, the model is used to predict distributions of athletic achievements across sports, geographical scale, and gender, from Grand Slam victories in tennis (male and female), major wins in golf (male and female), goals scored in ice hockey (male), and goals scored in soccer (male). Overall, the dynamic network model provides a comprehensive framework to understand the theoretical principles underlying the development of talent.

In the article "Categorical Cross-Recurrence Quantification Analysis Applied to Communicative Interaction during Ainsworth's Strange Situation" by D. Lira-Palma et al., a novel analysis of a well-known paradigm in developmental psychology is presented: the strange situation procedure for assessing children's attachment quality. Categorical (cross-) recurrence quantification analysis is used to study synchronization in the communicative interactions during the unfolding of this procedure, for two children and their caregivers. The authors extract and compare several recurrence measures from the time series of verbal and motor behaviors, at both the individual and dyadic level. Results emphasize the role of interpersonal coupling and synchronization in the strange situation procedure, which is different for verbal behaviors than for motor behaviors and for caregivers and strangers than for children.

\section{Conflicts of Interest}

The editors declare that they have no conflicts of interest regarding the publication of this special issue.

\author{
Ralf F. A. Cox \\ Ruud J. R. Den Hartigh \\ Michael J. Richardson \\ Chen $\mathrm{Yu}$ \\ Till D. Frank
}




\section{References}

[1] R. J. R. Den Hartigh, R. F. A. Cox, and P. L. C. Van Geert, "Complex versus complicated models of cognition," in Springer Handbook of Model-Based Science, L. Magnani and T. Bertolotti, Eds., Springer International Publishing, Cham, Switserland, 2017.

[2] M. J. Richardson, K. L. Marsh, and R. C. Schmidt, "Challenging the egocentric view of coordinated perceiving, acting and knowing," in Mind in Context, L. F. Barrett, B. Mesquita, and E. R. Smith, Eds., Guilford, New York, NY, USA, 2010.

[3] M. J. Richardson and R. W. Kallen, "Symmetry-breaking and the contextual emergence of human multiagent coordination and social activity," in Contextuality from Quantum Physics to Psychology, E. Dzhafarov, S. Jordan, R. Zhang, and V. Cervantes, Eds., pp. 229-286, World Scientific, 2015.

[4] C. Yu and L. B. Smith, "Multiple sensory-motor pathways lead to coordinated visual attention," Cognitive Science, vol. 41, pp. 5-31, 2017.

[5] T. L. Xu, D. Abney, and C. Yu, "Discovering multicausality in the development of coordinated behavior," in Proceedings of the 39th Annual Meeting of the Cognitive Science Society, London, UK, 2017.

[6] M. T. Turvey and C. Carello, "The surprising nature of the reaction time task," Ecological Psychology Journal, vol. 25, no. 3, pp. 226-232, 2013.

[7] E. Thelen and L. B. Smith, A Dynamic Systems Approach to the Development of Cognition and Action, The MIT Press, Cambridge, Mass, USA, 1994.

[8] P. Van Geert, Dynamic Systems of Development: Change between Complexity and Chaos, Harvester Wheatsheaf, 1994.

[9] M. J. Richardson, R. Dale, and K. L. Marsh, "Complex dynamical systems in social and personality psychology: theory, modeling and analysis," in Handbook of Research Methods in Social and Personality Psychology, H. T. Reis and C. M. Judd, Eds., pp. 253-282, Cambridge University Press, New York, NY, USA, 2nd edition, 2014.

[10] R. J. R. Den Hartigh, M. W. G. Van Dijk, H. W. Steenbeek, and P. L. C. Van Geert, "A dynamic network model to explain the development of excellent human performance," Frontiers in Psychology, vol. 7, 2016.

[11] N. M. P. De Ruiter, R. J. R. Den Hartigh, R. F. A. Cox, P. L. C. Van Geert, and E. S. Kunnen, "The temporal structure of state selfesteem variability during parent-adolescent interactions: more than random fluctuations," Self and Identity, vol. 14, no. 3, pp. 314-333, 2015.

[12] R. F. A. Cox and A. W. Smitsman, "Action-selection perseveration in young children: advances of a dynamic model," Developmental Psychobiology, vol. 61, pp. 43-55, 2019.

[13] R. F. A. Cox and M. Van Dijk, "Micro-development in parentchild conversations: From global changes to flexibility," Ecological Psychology, vol. 25, no. 3, pp. 304-315, 2013. 


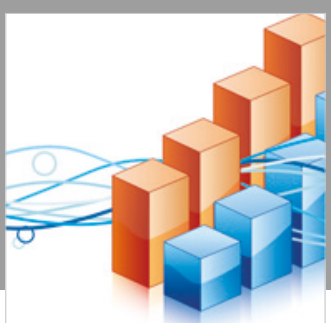

Advances in

Operations Research

\section{-n-m}
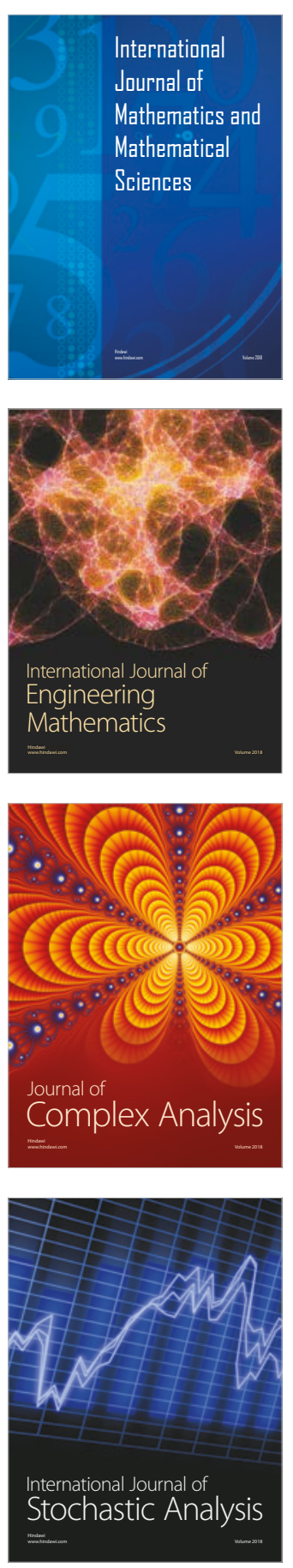
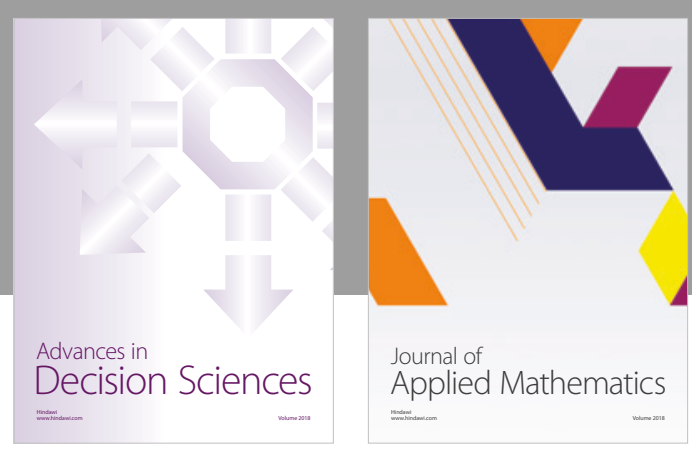

Journal of

Applied Mathematics
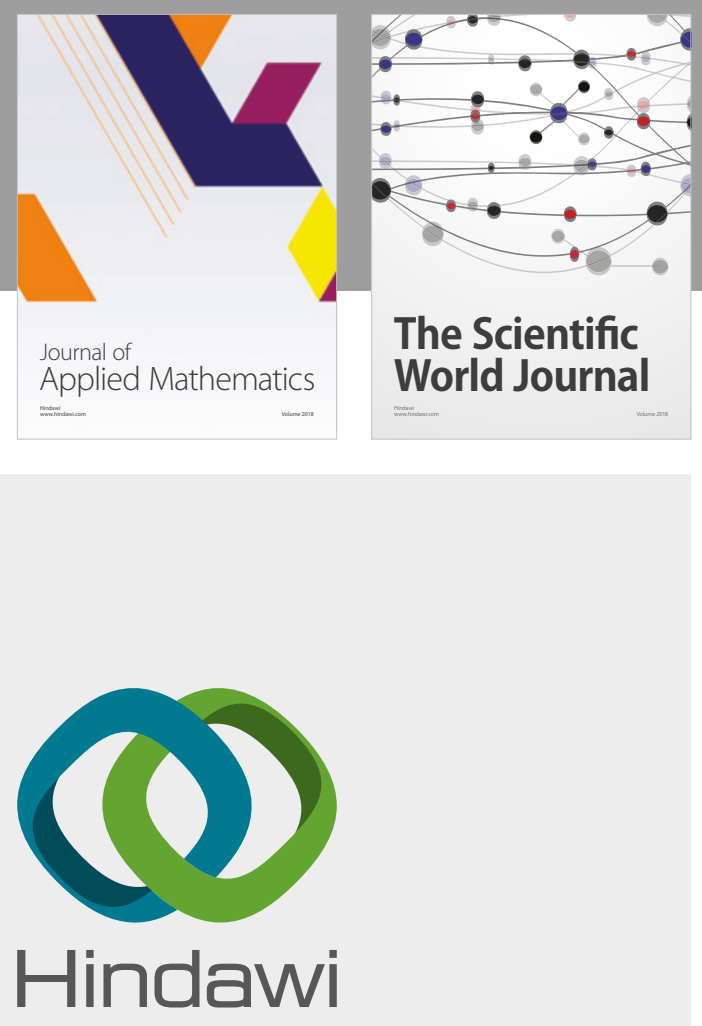

Submit your manuscripts at

www.hindawi.com

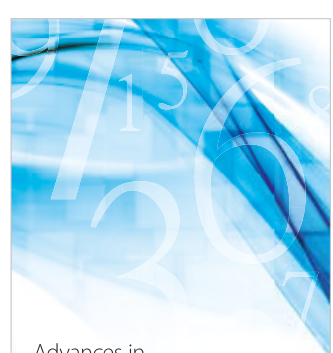

Advances in
Numerical Analysis
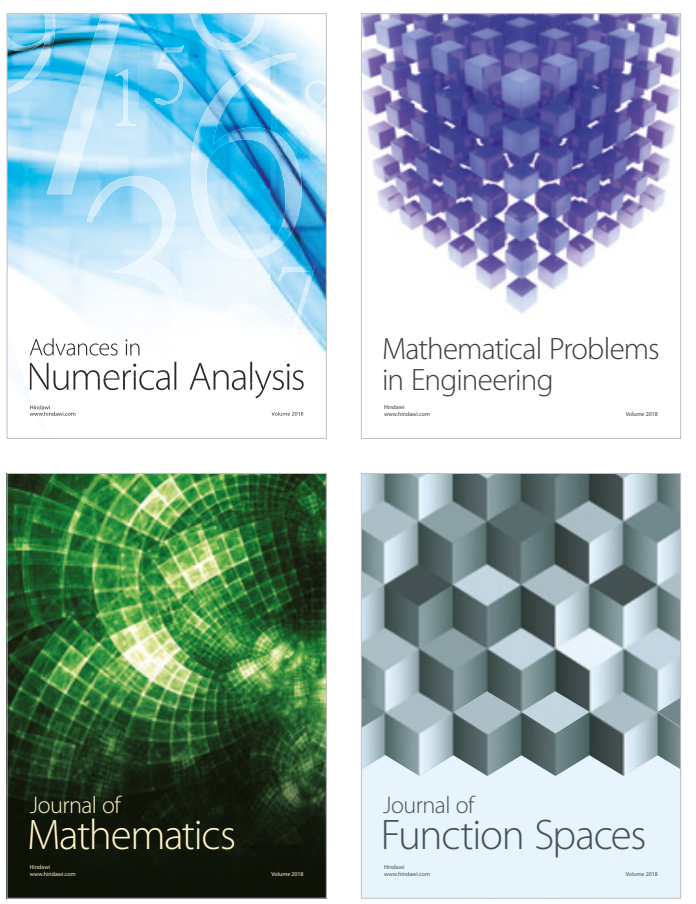

Mathematical Problems in Engineering

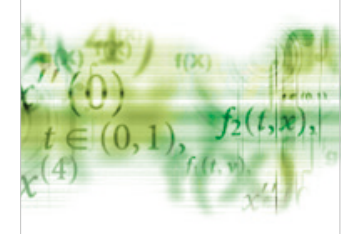

International Journal of

Differential Equations

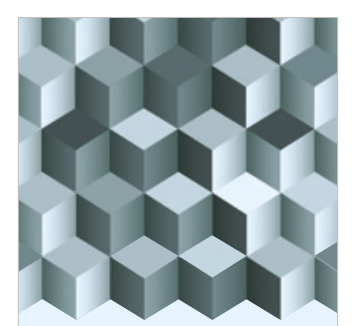

Journal of

Function Spaces
The Scientific

World Journal

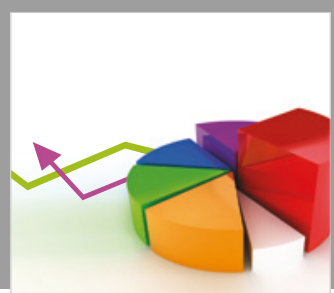

Journal of

Probability and Statistics
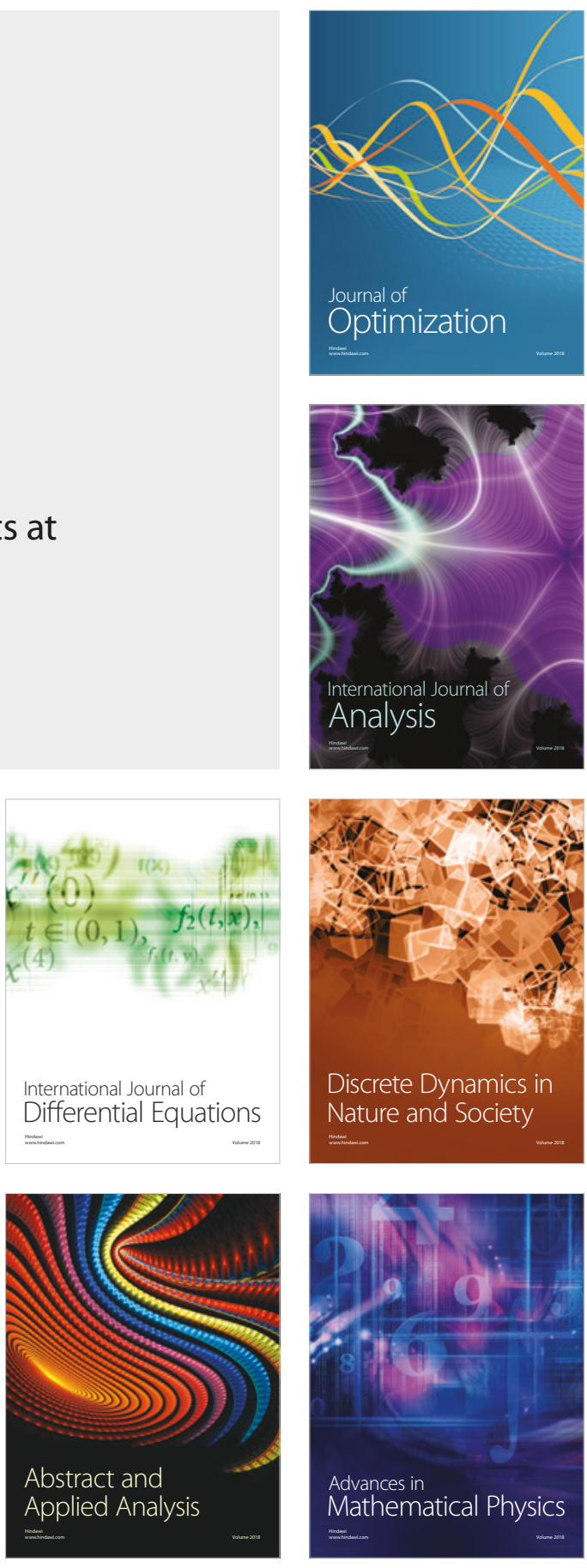